Article type : Original Article

\title{
Postoperative complications in individuals aged 70 and over undergoing elective surgery for colorectal cancer
}

\author{
Authors, affiliations: \\ Katleen Fagard ${ }^{1}$, Julie Casaer ${ }^{2}$, Albert Wolthuis ${ }^{3}$, Johan Flamaing ${ }^{1,4}$, Koen Milisen ${ }^{1,5}$, Jean-Pierre \\ Lobelle $^{6}$, Hans Wildiers ${ }^{7,8}$, Cindy Kenis ${ }^{1,8}$ \\ ${ }^{1}$ Department of Geriatric Medicine, University Hospitals Leuven, Leuven, Belgium; \\ ${ }^{2}$ Faculty of Medicine, KU Leuven, Leuven, Belgium; \\ ${ }^{3}$ Department of Abdominal Surgery, University Hospitals Leuven, Leuven, Belgium; \\ ${ }^{4}$ Department of Clinical and Experimental Medicine, KU Leuven, Leuven, Belgium; \\ ${ }^{5}$ Department of Public Health and Primary Care, Academic Centre for Nursing and Midwifery, KU \\ Leuven, Leuven, Belgium \\ ${ }^{6}$ Consultant in Statistics, Beernem, Belgium \\ ${ }^{7}$ Department of Oncology, KU Leuven, Leuven, Belgium; \\ ${ }^{8}$ Department of General Medical Oncology, University Hospitals Leuven, Leuven, Belgium
}

Key words:

Colorectal cancer, Surgery, Elderly, Postoperative complications, Outcomes

\section{Corresponding author}

Katleen Fagard

Tel.: +3216342640

Fax.: +3216342641

Herestraat 49, 3000 Leuven, Belgium

E-mail address: katleen.fagard@gmail.com

This article has been accepted for publication and undergone full peer review but has not been through the copyediting, typesetting, pagination and proofreading process, which may lead to differences between this version and the Version of Record. Please cite this article as doi: $10.1111 /$ codi. 13821

This article is protected by copyright. All rights reserved. 


\title{
Conflict of interest
}

None

\begin{abstract}
Aim:

This study aims to describe the nature, incidence, severity and outcomes of in-hospital postoperative complications (POCs) in older patients undergoing elective surgery for colorectal cancer (CRC).

Method:

Patients were identified from a prospectively collected database (2009-2015) focusing on the implementation of geriatric screening and assessment in patients with cancer. Medical and surgical POCs were retrieved retrospectively from the medical records, and the severity of the POCs was graded by the Clavien-Dindo (CD) grading system. The following outcomes were analyzed comparing patients with and without $C D \geq 2$ and $C D \geq 3$ POCs: length of stay (LOS), transfer to the intensive care unit (ICU), 30-day readmission rates, 30-day and 1-year mortality.
\end{abstract}

Results:

One hundred and ninety patients ( $\geq 70$ years old) were included. Medical POCs (40.5\%) were more frequent than surgical POCs (17.9\%); $37.9 \%$ experienced CD $\geq 2$ POCs. The most common medical POCs were: infections $(26.8 \%)$, transient confusion or altered mental function $(12,1 \%)$, cardiac arrhythmia (4.7\%), ileus/gastroparesis/prolonged recovery of transit (4.7\%). The most common surgical POCs were surgical site infections (12.1\%), wound dehiscence/bleeding (4.7\%), anastomotic leak (3.7\%) and surgical site bleeding (3.7\%). The reoperation rate was $7.9 \%$. CD $\geq 2$ POCs led to 11 ICU admissions and increased median postoperative LOS by $114 \%$ ( $P<0.0001$ for both), but did not significantly alter 30 -day readmission, 30 -day and 1-year mortality rates. $C D \geq 3$ POCs increased LOS by $162 \%,(p<0.0001)$ and showed an increased 1-year mortality $(p=0.07)$.

\section{Conclusion:}

This study shows that in-hospital medical and surgical complications after surgery for CRC in patients $\geq 70 y$ old are frequent and that complications lead to less favorable outcomes.

\section{What does this paper add to the literature?}

This paper analyzes postoperative complications in elderly colorectal cancer patients ( $\geq 70 \mathrm{y})$ in detail and compares the findings to the scarce literature in this age group. The overview can be used to inform elderly patients preoperatively about postoperative risks and to develop appropriate care plans for them in the surgical ward.

\section{Introduction}

Colorectal cancer (CRC) is the third leading cause of cancer worldwide. ${ }^{1}$ Almost $60 \%$ of new cases are diagnosed in patients aged 65 and over. ${ }^{2}$ In non-metastatic cancer, surgery is the cornerstone of cure. In more advanced stages, surgery can be indicated to gain relief of symptoms such as bleeding, obstruction and perforation. ${ }^{3-6}$ As a consequence, higher age or the presence of comorbidity do not significantly affect the resection rate. ${ }^{5,7-8}$

This article is protected by copyright. All rights reserved. 
Despite the benefits of surgery, the rate of adverse postoperative outcomes increases with advancing age. ${ }^{3,7,9}$ Older patients undergoing surgery have higher morbidity and mortality rates, longer lengths of hospital stay (LOS), higher readmission rates, and are more frequently not able to return home after discharge. ${ }^{7}$ In the older population, postoperative complications (POCs) are predominantly medical, rather than surgical. ${ }^{7,10}$ Mortality is high in emergency surgery, but elective surgery is relatively safe in the elderly. ${ }^{3,11-13}$ Moreover mortality rates have substantially declined over recent decades.. $7,9,14$

Even though life expectancy is increasing and the numbers of vulnerable older patients presenting for surgery is increasing, the elderly are often underrepresented in clinical trials, although in recent years there is more focus on older patients in surgical clinical trials. ${ }^{7,11,15-17}$ The aim of this study was to describe the nature, incidence, severity and outcomes of in-hospital postoperative complications (POCs) in individuals aged 70 and older operated on for colorectal cancer (CRC). Reported outcomes are length of stay (LOS), the number of transfers to the intensive care unit (ICU), 30-day and 1-year mortality and 30-day readmission rates.

\section{Method}

\section{STUDY DESIGN AND POPULATION}

The study population was derived from three, prospective, multicenter, non-interventional studies, performed between October 2009 and February 2015, evaluating the implementation of systematic geriatric screening and geriatric assessment (GA) in older patients with cancer. ${ }^{18-21}$ Patients aged 70 years and older with newly diagnosed cancer were included in the original studies when they presented for a cancer treatment decision. The original studies observed the relevance of the GA and the influence of the GA on treatment decisions, analyzed the given recommendations in order to standardize them, and observed the adherence to the geriatric recommendations. For this study, patients with CRC were selected if they scheduled for elective surgery in the University Hospitals of Leuven, Belgium after geriatric screening,. Patients planned for neo-adjuvant therapy before surgery were excluded. The original study protocol was approved by the Ethics Committee of the hospital (S51814, S51815, S54598). Informed consent was given by the patient or the patients appropriate surrogate decision maker.

\section{DATA COLLECTION AND OUTCOMES}

Data from the original database and additional data from the patients' medical records were collected retrospectively by 2 researchers (JC and KF).

Data recorded from the original database were the patients' age, gender, frailty status (measured by the G8 screening tool ${ }^{22}$ ), tumor stage and tumor location, the Charlson Comorbidity index (CCI) ${ }^{23-24}$, polypharmacy (defined as 5 or more medications per day) and the Eastern Cooperative Oncology Group Performance Status (ECOG-PS). ${ }^{25}$

In the absence of a prospective registration system for postoperative complications in our hospital, the American Society of Anaesthesiologists (ASA) physical status score ${ }^{26}$, the surgery performed, the surgical approach and the postoperative complications were retrospectively collected from the medical records. Complications that occurred during or after surgery (between the operation date and the discharge date and not present prior to surgery) were recorded. Besides screening the

This article is protected by copyright. All rights reserved. 
discharge letters, the full patients' medical records and notes were reviewed to confirm the diagnoses or to uncover diagnoses that were not mentioned in the discharge letters. POCs were clearly pre-defined, based on literature and clinical experience. These definitions were further adapted by consensus $(\mathrm{KF}, \mathrm{JC}$ ) to what could be reliably derived retrospectively from the electronic medical records. ${ }^{27-31}$ The definitions used are reported in Appendix $A$.

The following outcomes were retrieved from the medical records: the postoperative LOS (the number of postoperative days spent in the hospital until discharge or until transfer to a rehabilitation unit), the number of transfers to the ICU during hospital stay (due to postoperative complications) and the number of unplanned readmissions within 30 days of discharge. We also recorded the in-hospital mortality, the surgical mortality (within the first 30 postoperative days) and the 1-year mortality (within 1 year after the operation). If not mentioned in the medical records, mortality data were obtained from the national mortality registry.

Besides listing the complications and reporting the major categories, the postoperative adverse events were also classified into severity grades, using the Clavien-Dindo 2004 classification system. ${ }^{32}$

\section{STATISTICAL ANALYSIS}

Statistical analyses were performed with SAS version 9.3. Continuous data are reported using the median and the extremes. Categorical data are reported using percentage and $95 \%$ confidence intervals. Comparisons of continuous data were performed with non-parametric Wilcoxon tests. Comparisons of categorical data were performed with a Chi-Square test or with a Fisher's exact test.

\section{Results}

\section{PATIENT AND CLINICAL CHARACTERISTICS}

Figure 1 displays the patient selection and table 1 summarizes the patient and clinical characteristics. One hundred and ninety patients (105 men and 85 women) planned for elective CRC surgery, with a median age of 77 years (range 70-97), were included. One hundred and sixty-three patients (85.8\%) had colon cancer and 27 patients (14.2\%) had rectal cancer. Metastatic disease was present in $14.7 \%$. One hundred and fifteen patients $(60.5 \%)$ screened positive for frailty with the G8 screening tool. Most of the patients (97.9\%) were classified as ASA II or III and more than half $(55.8 \%)$ had comorbidities preoperatively. Polypharmacy was present in $47.4 \%$ of the patients. The majority of the patients had a good ECOG performance status ( $86.9 \%$ scored 0 or 1 ). Half of the patients $(50.5 \%)$ had a laparoscopic operation. The three most common operations were right hemicolectomy $(41.6 \%)$, high anterior resection (26.8\%) and total mesorectal excision (8.9\%).

\section{POSTOPERATIVE COMPLICATIONS}

Medical POCs occurred in $40.5 \%$ of the patients and $17.9 \%$ had surgical POCs. Eight patients $(4.2 \%)$ had surgical POCs only, 51 (26.8\%) had medical POCs only and $26(13.7 \%)$ had medical and surgical POCs. Forty-two patients (22.1\%) had $\geq 2$ complications. The complications are displayed in table 2 .

\section{Medical complications}

Infectious complications were the most common medical POCs and occurred in $26.8 \%$ of the patients. The nature of the infections is shown in table 2 . The most common infection was urinary tract infection, followed by lower respiratory tract infections and catheter sepsis. Other medical

This article is protected by copyright. All rights reserved. 
complications in descending order and grouped by organ system were: neurological (12.6\%), cardiovascular (5.8\%), non-infectious abdominal (5.3\%), non-infectious urinary (3.7\%), non-infectious respiratory $(2.6 \%)$ and thromboembolic $(1.6 \%)$ complications. None of the patients suffered from (other than surgical) bleeding. Details of medical POCs are illustratedin Table 2.

\section{Surgical complications}

The most common surgical POCs were surgical site infections (SSI), occurring in $12.1 \%$ of the study population. Anastomotic leak occurred in $3.7 \%$ of patients.. Surgical site bleeding complicated the postoperative course in $3.7 \%$ of the patients. Seventeen patients $(7.9 \%)$ required reoperation before discharge. Other surgical POCs and their rates are shown in table 2.

\section{Severity of postoperative complications}

In table 3 the recorded POCs are stratified by severity using the Clavien-Dindo Classification system. Seventy-two patients (37.9\%) experienced Clavien-Dindo grade 2 and above (CD $\geq 2)$ POCs. Twenty patients (10.5\%) experienced Clavien-Dindo grade 3 and above $(C D \geq 3)$ POCs, and $2(1.1 \%)$ patients died during hospitalization.

\section{OUTCOMES}

The median postoperative LOS was 8 days (range 3-96). Eleven patients (5.8\%) needed transfer to ICU during their hospital stay. Unplanned readmission within 30 days of discharge occurred in 16 patients $(8.4 \%)$. Three patients (1.6\%) died within the first 30 postoperative days, of whom 2 died inhospital (1.1\%). The 1-year mortality rate was $12.1 \%(n=23)$.

The outcomes of patients with $C D \geq 2$ POCs, compared to patients with $C D<2$ POCs, are described in table 4. CD $\geq 2$ POCs led to $11 \mathrm{ICU}$ admissions ( $15.3 \%$ of the patients with $C D \geq 2 \mathrm{POCs}$ ) and increased the median postoperative LOS from 7 to 15 days, plus $114 \%$ ( $p<0.0001$ for both), but did not significantly alter 30-day readmission rates and 30-day and 1-year mortality rates. Two patients (one operated on laparoscopically and one that underwent open surgery) died of POCs in the hospital, both in the ICU, and 1 patient, that underwent open surgery and did not experience in-hospital complications, died within 30 days of discharge.

The outcomes of patients with $\mathrm{CD} \geq 3$ POCs (complications requiring surgical, endoscopic or radiological intervention or ICU transfer), compared to patients with $C D<3 P O C s$, are described in table 5 . CD $\geq 3$ POCs increased the median postoperative LOS by $162 \%$, from 8 to 21 days $(p<0.0001)$, and were associated with increased 1-year mortality $(p=0.07)$, but did not significantly alter 30 -day readmission and 30-day mortality rates.

\section{Discussion}

This study describes POCs and outcomes in patients aged 70 and older undergoing CRC surgery. POCs were frequent and more often medical than surgical. The 3 most common medical POCs in descending order were urinary tract infections, postoperative confusion or altered mental function and respiratory tract infections. Surgical site infections were the most common surgical POCs. POCs graded $\geq 2$ (by the Clavien-Dindo severity grading system) led to ICU-transfers and longer hospital stays but did not significantly alter unplanned 30-day readmissions and 30-day and 1-year mortality rates. The results were comparable for $C D \geq 3$ POCs, but the latter did show increased 1-year mortality.

This article is protected by copyright. All rights reserved. 
Defining the POCs was challenging. The literature describing postoperative outcomes in older patients after surgery for CRC is scarce. Moreover, reporting of outcomes often focusses on mortality and on surgical complications or classification of complications into organ systems or severity scores. Medical complications are less often reported in detail. A validated method to record postoperative complications prospectively is the Postoperative Morbidity Survey (POMS). ${ }^{33}$ Davies et al. proved its validity in major abdominal surgery. ${ }^{28}$ For the retrospective reporting of complications there is no standard method, although Patel et al. showed non-inferiority of retrospective compared to prospective data collection using the POMS in a recent study, including 85 patients undergoing major elective surgery. ${ }^{34}$ This method however does not differentiate between medical and surgical complications and classifies the complications into 9 domains (pulmonary, infectious, renal, gastrointestinal, cardiovascular, neurological, wound complications, hematological, pain) without further differentiation. Because the aim of this study is to give a detailed overview of the nature of the complications in our study population, we adapted definitions from the literature to the complications encountered and to what could be reliably derived in a retrospective way from the electronic medical records in our center.

Comparison of our results to the results of studies in similar age groups is difficult because, apart from differences in patient selection, many studies do not specify the definitions used ${ }^{15,35-37}$, do not use exactly the same definitions or derive the data from ICD-9 coding. ${ }^{7,38}$ In all of the studies, as in ours, infectious complications are more common than others. Compared to recent studies in similar age groups we found higher rates of urinary tract infection and relatively high rates of pneumonia. ${ }^{7}$ 15, 35-38 Overall both infectious complications are prevalent in the immediate postoperative period after CRC surgery. The rate of cardiac complications was similar to other studies: arrhythmia around $4 \%$, heart failure around 2.5 to $3 \%$ and myocardial ischemia around 0.5 to $2.5 \% .{ }^{15,36-37}$ In our series, apart from catheter thrombosis, we did not find any other thromboembolic complications, such as deep venous leg thrombosis, pulmonary embolism or stroke. In other series the rates of those complications are low ranging from 0.2 to $2.5 \% .{ }^{15,35-37,39}$ The above mentioned complication rates are in line with a review reporting postoperative complications by age-group. ${ }^{3}$ Because postoperative delirium was not assessed in a standardized way on the surgical ward, e.g. using a Confusion Assessment Method $(\mathrm{CAM})^{40}$ or Delirium Observation Screening (DOS) ${ }^{41}$ scale, we only recorded transient postoperative confusion or transient depression of cerebral function when reported in the electronic medical record. This makes it difficult to differentiate between delirium, dementia, depression or other reasons for agitation or sedation and does not reflect the real incidence of postoperative delirium in our population. Prospective measurement with validated scales in elective elderly surgical CRC patients reveals incidence rates of postoperative delirium of $11-31 \% .{ }^{42-45}$ Comparable articles report variable rates of surgical site infections in older age groups, although the mean incidence is similar to our findings. ${ }^{15,35-37}$ The incidence of anastomotic leakage is comparable to other studies ${ }^{3,15,35-36}$, except two studies that report higher rates. ${ }^{7,}{ }^{37}$ Despite the older study population, the substantial level of comorbidity, and the burden of postoperative complications, the 30 -day mortality was very low in our study $(1,6 \%)$. A review by Mamidanna et al. examining the postoperative mortality risk in patients over 70 undergoing elective colorectal resection reports mortality rates from 0 to $13.3 \%$, and the majority of the included studies reported higher mortality rates than our study. ${ }^{12}$ Mortality at one year is comparable to other studies. ${ }^{8,14,46-}$ ${ }^{47}$ In our study mortality rates were not significantly affected by the occurrence of $C D \geq 2 P O C s, C D \geq 3$ POCs were associated with an increased 1-year mortality.

This study has several strengths and learning points. The definitions used for POCs were clearly defined. The study provides information to clinicians regarding the in-hospital postoperative course in older patients with CRC, and can be used to inform patients preoperatively about postoperative risks and to develop appropriate care plans in the surgical ward. ${ }^{7}$ The measurement and reporting of outcomes can lead to measures to improve the safety and quality of care and allows comparison between health care providers. ${ }^{50,52,55-56}$ The study compares outcomes of patients with and without

This article is protected by copyright. All rights reserved. 
complications: POCs graded $\geq 2$ by the Clavien-Dindo grading system led to higher postoperative LOS (plus 8 days median stay for $C D \geq 2$ POCs and plus 13 days for $C D \geq 3$ POCs), and transfer to the ICU (15.3\% of the patients with $C D \geq 2$ POCs), which has a considerable impact on health care costs as shown by various authors. ${ }^{48-51}$ Efforts should be made to optimize recognition and management of surgical as well as medical POCs. ${ }^{47,52}$ Surgeons should have medical expertise concerning the most common medical POCs and for vulnerable, multimorbid older patients collaboration with paramedics and other medical specialties is mandatory. ${ }^{5,10,16,53-54}$

The main limitations of our study were fivefold. First, the retrospective study design, with inclusion of a sub-cohort of patients from another study, and limitation to a single center. Second, the inclusion of a heterogeneous population regarding tumor stage, tumor location, surgical approach, type of surgery and frailty status. Third, the lack of a prospective registration system for postoperative complications in our hospital and in our country. Fourth, the absence of internationally standardized definitions to retrieve postoperative complications in detail from the medical records in a retrospective way. Fifth, we did not look at interventions to improve postoperative outcomes.

Future research needs to focus on interventions to reduce the postoperative complication rates in older surgical patients. For example, new risk stratification strategies for older patients undergoing CRC surgery based on geriatric assessment or frailty screening, pre-habilitation strategies, the application of ERAS principles, but also the effect of applying geriatric interventions based on geriatric assessment results and the effect of multimodal approaches, for instance geriatric-surgical co-management programs.

\section{Conclusion}

Elderly CRC patients pose a challenge in the postoperative period because of high medical and surgical complication rates, leading to higher of ICU use and longer hospital stays. In-hospital mortality is relatively low and post-discharge readmission and mortality were not significantly affected by the occurrence of $C D \geq 2$ POCs in our study, while $C D \geq 3$ POCs did show an association with increased 1-year mortality.

Acknowledgements: The authors would like to thank all patients, trained health care workers and treating physicians involved in the original study that was supported by a grant from 'Kom op tegen Kanker' and 'Cancer Plan Belgium'. HW is a recipient of the 'Fonds voor Wetenschappelijk Onderzoek - Vlaanderen (FWO).'

\section{References}

1. Haggar FA, Boushey RP. Colorectal cancer epidemiology: incidence, mortality, survival, and risk factors. Clin Colon Rectal Surg. 2009;22(4):191-7.

2. Audisio RA, Pope D, Ramesh HS, Gennari R, van Leeuwen BL, West C, et al. Shall we operate? Preoperative assessment in elderly cancer patients (PACE) can help. A SIOG surgical task force prospective study. Crit Rev Oncol Hematol. 2008;65(2):156-63.

3. Surgery for colorectal cancer in elderly patients: a systematic review. Colorectal Cancer Collaborative Group. Lancet. 2000;356(9234):968-74.

This article is protected by copyright. All rights reserved. 
4. Chang GJ. Challenge of primary tumor management in patients with stage IV colorectal cancer. J Clin Oncol. 2012;30(26):3165-6.

5. Janssen-Heijnen ML, Maas HA, Houterman S, Lemmens VE, Rutten HJ, Coebergh JW. Comorbidity in older surgical cancer patients: influence on patient care and outcome. Eur J Cancer. 2007;43(15):2179-93.

6. Kristjansson SR, Farinella E, Gaskell S, Audisio RA. Surgical risk and post-operative complications in older unfit cancer patients. Cancer Treat Rev. 2009;35(6):499-502.

7. Jafari MD, Jafari F, Halabi WJ, Nguyen VQ, Pigazzi A, Carmichael JC, et al. Colorectal Cancer Resections in the Aging US Population: A Trend Toward Decreasing Rates and Improved Outcomes. JAMA Surg. 2014;149(6):557-64.

8. Neuman HB, O'Connor ES, Weiss J, Loconte NK, Greenblatt DY, Greenberg CC, et al. Surgical treatment of colon cancer in patients aged 80 years and older : analysis of 31,574 patients in the SEER-Medicare database. Cancer. 2013;119(3):639-47.

9. Tan E, Tilney H, Thompson M, Smith J, Tekkis PP. The United Kingdom National Bowel Cancer Project -- epidemiology and surgical risk in the elderly. Eur J Cancer. 2007;43(15):2285-94.

10. Partridge JS, Harari D, Martin FC, Dhesi JK. The impact of pre-operative comprehensive geriatric assessment on postoperative outcomes in older patients undergoing scheduled surgery: a systematic review. Anaesthesia. 2014;69 Suppl 1:8-16.

11. Audisio RA, Papamichael D. Treatment of colorectal cancer in older patients. Nat Rev Gastroenterol Hepatol. 2012;9(12):716-25.

12. Mamidanna R, Almoudaris AM, Faiz O. Is 30-day mortality an appropriate measure of risk in elderly patients undergoing elective colorectal resection? Colorectal Dis. 2012;14(10):1175-82.

13. Stepien R, Gluszek S, Koziel D, Kaczmarczyk M. The risk of surgical treatment in patients aged 85+, with special consideration of colorectal cancer. Pol Przegl Chir. 2014;86(3):132-40.

14. Hamaker ME, Schiphorst AH, Verweij NM, Pronk A. Improved survival for older patients undergoing surgery for colorectal cancer between 2008 and 2011. Int J Colorectal Dis. 2014;29(10):1231-6.

15. Duraes LC, Stocchi L, Dietz D, Kalady MF, Kessler H, Schroeder D, et al. The Disproportionate Effect of Perioperative Complications on Mortality within 1 Year After Colorectal Cancer Resection in Octogenarians. Ann Surg Oncol. 2016.

16. Ugolini G, Ghignone F, Zattoni D, Veronese G, Montroni I. Personalized surgical management of colorectal cancer in elderly population. World J Gastroenterol. 2014;20(14):3762-77.

17. Fagard K, Leonard S, Deschodt M, Devriendt E, Wolthuis A, Prenen H, et al. The impact of frailty on postoperative outcomes in individuals aged 65 and over undergoing elective surgery for colorectal cancer: A systematic review. J Geriatr Oncol. 2016;7(6):479-91.

18. Baitar A, Kenis C, Moor R, Decoster L, Luce S, Bron D, et al. Implementation of geriatric assessment-based recommendations in older patients with cancer: A multicentre prospective study. J Geriatr Oncol. 2015;6(5):401-10.

19. Kenis C, Bron D, Libert Y, Decoster L, Van Puyvelde K, Scalliet P, et al. Relevance of a systematic geriatric screening and assessment in older patients with cancer: results of a prospective multicentric study. Ann Oncol. 2013;24(5):1306-12.

20. Kenis C, Flamaing J, Debruyne P, Rasschaert M, Focan C, Cornelis F, et al. A nationwide implementation of a multidisciplinary geriatric assessment and intervention program in belgian older patients with cancer. Journal of Geriatric Oncology. 2015;6(S13-S27):abstract 001.

21. Kenis C, Decoster L, Van Puyvelde K, De Greve J, Conings G, Milisen K, et al. Performance of two geriatric screening tools in older patients with cancer. J Clin Oncol. 2014;32(1):19-26.

22. Bellera CA, Rainfray M, Mathoulin-Pelissier S, Mertens C, Delva F, Fonck M, et al. Screening older cancer patients: first evaluation of the G-8 geriatric screening tool. Ann Oncol. 2012;23(8):2166-72.

23. Charlson ME, Pompei P, Ales KL, Mackenzie CR. A new method of classifying prognostic comorbidity in longitudinal studies: development and validation. J Chronic Dis. 1987;40(5):373-83.

This article is protected by copyright. All rights reserved. 
24. Frenkel WJ, Jongerius EJ, Mandjes-van Uitert MJ, van Munster BC, de Rooij SE. Validation of the Charlson Comorbidity Index in acutely hospitalized elderly adults: a prospective cohort study. J Am Geriatr Soc. 2014;62(2):342-6.

25. Oken MM, Creech RH, Tormey DC, Horton J, Davis TE, McFadden ET, et al. Toxicity and response criteria of the Eastern Cooperative Oncology Group. Am J Clin Oncol. 1982;5(6):649-55.

26. Owens WD, Felts JA, Spitznagel EL, Jr. ASA physical status classifications: a study of consistency of ratings. Anesthesiology. 1978;49(4):239-43.

27. Jammer I, Wickboldt N, Sander M, Smith A, Schultz MJ, Pelosi P, et al. Standards for definitions and use of outcome measures for clinical effectiveness research in perioperative medicine: European Perioperative Clinical Outcome (EPCO) definitions: a statement from the ESAESICM joint taskforce on perioperative outcome measures. Eur J Anaesthesiol. 2015;32(2):88-105.

28. Davies SJ, Francis J, Dilley J, Wilson RJ, Howell SJ, Allgar V. Measuring outcomes after major abdominal surgery during hospitalization: reliability and validity of the Postoperative Morbidity Survey. Perioper Med (Lond). 2013;2(1):1.

29. Jakobson T, Karjagin J, Vipp L, Padar M, Parik AH, Starkopf L, et al. Postoperative complications and mortality after major gastrointestinal surgery. Medicina (Kaunas). 2014;50(2):1117.

30. van Vugt JL, Cakir H, Kornmann VN, Doodeman HJ, Stoot JH, Boerma D, et al. The new Body Mass Index as a predictor of postoperative complications in elective colorectal cancer surgery. Clin Nutr. 2015;34(4):700-4.

31. McSorley ST, Horgan PG, McMillan DC. The impact of the type and severity of postoperative complications on long-term outcomes following surgery for colorectal cancer: A systematic review and meta-analysis. Crit Rev Oncol Hematol. 2016;97:168-77.

32. Dindo D, Demartines N, Clavien PA. Classification of surgical complications: a new proposal with evaluation in a cohort of 6336 patients and results of a survey. Ann Surg. 2004;240(2):205-13.

33. Bennett-Guerrero E, Welsby I, Dunn TJ, Young LR, WahI TA, Diers TL, et al. The use of a postoperative morbidity survey to evaluate patients with prolonged hospitalization after routine, moderate-risk, elective surgery. Anesth Analg. 1999;89(2):514-9.

34. Patel AB, Reyes A, Ackland GL. Non-inferiority of retrospective data collection for assessing perioperative morbidity. PeerJ. 2015;3:e1466.

35. Kristjansson SR, Jordh øy MS, Nesbakken A, Skovlund E, Bakka A, Johannessen H-O, et al. Which elements of a comprehensive geriatric assessment (CGA) predict post-operative complications and early mortality after colorectal cancer surgery? Journal of Geriatric Oncology. 2010;1(2):57-65.

36. Tan KY, Kawamura YJ, Tokomitsu A, Tang T. Assessment for frailty is useful for predicting morbidity in elderly patients undergoing colorectal cancer resection whose comorbidities are already optimized. Am J Surg. 2012;204(2):139-43.

37. Tominaga T, Takeshita H, Takagi K, Kunizaki M, To K, Abo T, et al. E-PASS score as a useful predictor of postoperative complications and mortality after colorectal surgery in elderly patients. Int J Colorectal Dis. 2016;31(2):217-25.

38. Sheka AC, Tevis S, Kennedy GD. Urinary tract infection after surgery for colorectal malignancy: risk factors and complications. Am J Surg. 2016;211(1):31-9.

39. Grosso G, Biondi A, Marventano S, Mistretta A, Calabrese G, Basile F. Major postoperative complications and survival for colon cancer elderly patients. BMC Surg. 2012;12 Suppl 1:S20.

40. Inouye SK, van Dyck CH, Alessi CA, Balkin S, Siegal AP, Horwitz RI. Clarifying confusion: the confusion assessment method. A new method for detection of delirium. Ann Intern Med. 1990;113(12):941-8.

41. Schuurmans MJ, Shortridge-Baggett LM, Duursma SA. The Delirium Observation Screening Scale: a screening instrument for delirium. Res Theory Nurs Pract. 2003;17(1):31-50.

This article is protected by copyright. All rights reserved. 
42. Mokutani Y, Mizushima T, Yamasaki M, Rakugi H, Doki Y, Mori M. Prediction of Postoperative Complications Following Elective Surgery in Elderly Patients with Colorectal Cancer Using the Comprehensive Geriatric Assessment. Dig Surg. 2016;33(6):470-7.

43. Raats JW, Steunenberg SL, Crolla RM, Wijsman JH, te Slaa A, van der Laan L. Postoperative delirium in elderly after elective and acute colorectal surgery: A prospective cohort study. Int I Surg. 2015;18:216-9.

44. Tei M, Ikeda M, Haraguchi N, Takemasa I, Mizushima T, Ishii H, et al. Risk factors for postoperative delirium in elderly patients with colorectal cancer. Surg Endosc. 2010;24(9):2135-9.

45. Tei M, Wakasugi M, Kishi K, Tanemura M, Akamatsu H. Incidence and risk factors of postoperative delirium in elderly patients who underwent laparoscopic surgery for colorectal cancer. Int J Colorectal Dis. 2016;31(1):67-73.

46. Dekker JW, Gooiker GA, Bastiaannet E, van den Broek CB, van der Geest LG, van de Velde CJ, et al. Cause of death the first year after curative colorectal cancer surgery; a prolonged impact of the surgery in elderly colorectal cancer patients. Eur J Surg Oncol. 2014;40(11):1481-7.

47. Gooiker GA, Dekker JW, Bastiaannet E, van der Geest LG, Merkus JW, van de Velde CJ, et al. Risk factors for excess mortality in the first year after curative surgery for colorectal cancer. Ann Surg Oncol. 2012;19(8):2428-34.

48. Bailey JG, Davis PJ, Levy AR, Molinari M, Johnson PM. The impact of adverse events on health care costs for older adults undergoing nonelective abdominal surgery. Can J Surg. 2016;59(3):172-9.

49. Khan NA, Quan H, Bugar JM, Lemaire JB, Brant R, Ghali WA. Association of postoperative complications with hospital costs and length of stay in a tertiary care center. J Gen Intern Med. 2006;21(2):177-80.

50. Mathis KL, Cima RR. Quality assurance in colon and rectal cancer surgery. Surg Oncol Clin N Am. 2014;23(1):11-23.

51. Regenbogen SE, Veenstra CM, Hawley ST, Banerjee M, Ward KC, Kato I, et al. The personal financial burden of complications after colorectal cancer surgery. Cancer. 2014;120(19):3074-81.

52. Henneman D, Ten Berge MG, Snijders HS, van Leersum NJ, Fiocco M, Wiggers T, et al. Safety of elective colorectal cancer surgery: non-surgical complications and colectomies are targets for quality improvement. J Surg Oncol. 2014;109(6):567-73.

53. Dewan SK, Zheng SB, Xia SJ. Preoperative geriatric assessment: comprehensive, multidisciplinary and proactive. Eur J Intern Med. 2012;23(6):487-94.

54. Tan HJ, Saliba D, Kwan L, Moore AA, Litwin MS. Burden of Geriatric Events Among Older Adults Undergoing Major Cancer Surgery. J Clin Oncol. 2016;34(11):1231-8.

55. Mazeh H, Samet Y, Abu-Wasel B, Beglaibter N, Grinbaum R, Cohen T, et al. Application of a novel severity grading system for surgical complications after colorectal resection. J Am Coll Surg. 2009;208(3):355-61.

56. Schilling PL, Dimick JB, Birkmeyer JD. Prioritizing quality improvement in general surgery. J Am Coll Surg. 2008;207(5):698-704.

This article is protected by copyright. All rights reserved. 
Table 1: Patient and clinical characteristics $(n=190)$

\begin{tabular}{|c|c|c|c|c|}
\hline & & $n$ & $\%$ & $95 \% \mathrm{Cl}$ \\
\hline Age & \multicolumn{4}{|c|}{ Median (range): 77 (70-97) years } \\
\hline \multirow[t]{2}{*}{ Gender } & Female & 85 & 44.7 & $37.7-51.8$ \\
\hline & Male & 105 & 55.3 & $48.2-62.3$ \\
\hline \multirow[t]{2}{*}{ G8 score $^{1}$} & > 14 (screening for frailty negative) & 75 & 39.5 & $32.5-46.4$ \\
\hline & $\leq 14$ (screening for frailty positive) & 115 & 60.5 & $53.6-67.5$ \\
\hline \multirow{4}{*}{$\begin{array}{l}\text { Tumor stage } \\
\text { (AJCC) }\end{array}$} & 1 & 42 & 22.1 & $16.2-28.0$ \\
\hline & II & 60 & 31.6 & $25.0-38.2$ \\
\hline & III & 60 & 31.6 & $25.0-38.2$ \\
\hline & IV & 28 & 14.7 & $9.7-19.8$ \\
\hline \multirow[t]{2}{*}{ Tumor location } & Colon & 163 & 85.8 & $80.8-90.8$ \\
\hline & Rectum & 27 & 14.2 & $9.3-19.2$ \\
\hline \multirow{3}{*}{$\begin{array}{l}\text { Surgical } \\
\text { approach }\end{array}$} & Laparoscopic & 96 & 50.5 & $43.4-57.6$ \\
\hline & Open & 75 & 39.5 & $32.5-46.4$ \\
\hline & Converted (laparoscopic to open) & 19 & 10.0 & $5.7-14.3$ \\
\hline \multirow{10}{*}{$\begin{array}{l}\text { Surgery } \\
\text { performed }\end{array}$} & $\mathrm{RHC}$ & 79 & 41.6 & $34.6-48.6$ \\
\hline & LHC & 9 & 4.7 & $1.7-7.8$ \\
\hline & AR & 51 & 26.8 & $20.5-33.1$ \\
\hline & IRA & 2 & 1.1 & $0.0-2.5$ \\
\hline & APER & 11 & 5.8 & $2.5-9.1$ \\
\hline & $\mathrm{HP}$ & 10 & 5.3 & $2.1-8.4$ \\
\hline & TME & 17 & 8.9 & $4.9-13.0$ \\
\hline & $\mathrm{PP}$ & 6 & 3.2 & $0.7-5.6$ \\
\hline & Combination: $\mathrm{RHC}+\mathrm{AR}$ & 4 & 2.1 & $0.1-4.1$ \\
\hline & Combination: $L H C+$ APER & 1 & 0.5 & $0-1.6$ \\
\hline \multirow[t]{5}{*}{ ASA score } & I & 3 & 1.6 & $0-3.4$ \\
\hline & II & 93 & 48.9 & $41.8-56.1$ \\
\hline & III & 93 & 48.9 & $41.8-56.1$ \\
\hline & IV & 1 & 0.5 & 0-1.6 \\
\hline & V & 0 & 0 & $0-0$ \\
\hline \multirow{2}{*}{$\begin{array}{l}\text { Comorbidity } \\
\text { (CCI) }\end{array}$} & 0 & 84 & 44.2 & $37.2-51.3$ \\
\hline & $\geq 1$ & 106 & 55.8 & 48.7-62.9 \\
\hline \multirow[t]{2}{*}{ Polypharmacy } & No (<5 medications) & 100 & 52.6 & $45.5-59.7$ \\
\hline & Yes ( $\geq 5$ medications) & 90 & 47.4 & $40.3-54.5$ \\
\hline \multirow[t]{5}{*}{ ECOG-PS } & 0 (asymptomatic) & 83 & 43.7 & $36.6-50.7$ \\
\hline & 1 (symptomatic but completely ambulatory) & 82 & 43.2 & 36.1-50.2 \\
\hline & 2 (symptomatic, $<50 \%$ in bed during the day) & 16 & 8.4 & $4.5-12.4$ \\
\hline & 3 (symptomatic, $>50 \%$ in bed) & 9 & 4.7 & $1.7-7.8$ \\
\hline & 4 (bedbound) & 0 & 0 & $0-0$ \\
\hline
\end{tabular}

LEGEND: American Joint Committee on Cancer (AJCC) staging system; RHC: right hemicolectomy; LHC: left hemicolectomy; AR: high anterior resection; IRA: total colectomy with ileorectal anastomosis; APER: abdominoperineal excision of the rectum; HP: Hartmann procedure; TME: total mesorectal excision; PP: palliative procedure (stoma or segmental colectomy); ASA: American Society of Anesthesiologists; CCI: Charlson comorbidity index (0-37); ECOG-PS: Eastern Cooperative Oncology Group Performance Status; ${ }^{1}$ G8: screening tool for frailty.

This article is protected by copyright. All rights reserved. 
Table 2: Incidence of in-hospital postoperative complications ( $n=190)$

\begin{tabular}{|c|c|c|c|}
\hline & $\mathbf{n}$ & $\%$ & $95 \% \mathrm{Cl}$ \\
\hline MEDICAL complications & 77 & 40.5 & $33.5-47.5$ \\
\hline $\begin{array}{ll}\text { Infection } \\
\text { - } & \text { Lower respiratory tract infection } \\
\text { - } & \text { Urinary tract infection } \\
- & \text { Cholecystitis/cholangitis } \\
\text { - } & \text { Catheter sepsis } \\
- & \text { Septic shock } \\
\text { - } & \text { Other }\end{array}$ & $\begin{array}{c}51 \\
14 \\
32 \\
3 \\
11 \\
1 \\
5\end{array}$ & $\begin{array}{c}26.8 \\
7.4 \\
16.8 \\
1.6 \\
5.8 \\
0.5 \\
2.6\end{array}$ & $20.5-33.1$ \\
\hline $\begin{array}{l}\text { Respiratory (non-infectious) } \\
\text { - Prolonged respiratory symptoms without the need of } \\
\text { antibiotics or diuretics, including non-infectious COPD } \\
\text { exacerbations }\end{array}$ & $\begin{array}{l}5 \\
5\end{array}$ & $\begin{array}{l}2.6 \\
2.6\end{array}$ & $0.4-4.9$ \\
\hline $\begin{array}{l}\text { Cardiovascular } \\
\text { - Cardiac arrhythmia } \\
\text { - } \quad \text { Cardiac arrest } \\
\text { - } \quad \text { Acute myocardial ischemia } \\
\text { - } \quad \text { Heart failure }\end{array}$ & $\begin{array}{c}11 \\
9 \\
2 \\
1 \\
6\end{array}$ & $\begin{array}{l}5.8 \\
4.7 \\
1.1 \\
0.5 \\
3.2\end{array}$ & $2.5-9.1$ \\
\hline $\begin{array}{l}\text { Thromboembolic } \\
\text { - } \quad \text { Catheter thrombosis } \\
\text { - } \quad \text { Deep venous leg thrombosis } \\
\text { - } \quad \text { Pulmonary embolism }\end{array}$ & $\begin{array}{l}3 \\
3 \\
0 \\
0\end{array}$ & $\begin{array}{c}1.6 \\
1.6 \\
0 \\
0\end{array}$ & $0-3.4$ \\
\hline $\begin{aligned} & \text { Neurological } \\
& \text { - } \text { Stroke (CVA/TIA) } \\
&- \text { Transient confusion or altered mental function } \\
&- \text { Epileptic insult }\end{aligned}$ & $\begin{array}{c}24 \\
0 \\
23 \\
1\end{array}$ & $\begin{array}{c}12.6 \\
0 \\
12.1 \\
0.5\end{array}$ & $7.9-17.4$ \\
\hline $\begin{aligned} \text { Abdominal (non-infectious) } \\
-\quad \text { Ileus or gastroparesis or prolonged recovery of transit } \\
-\quad \text { Ischemic colitis }\end{aligned}$ & $\begin{array}{c}10 \\
9 \\
1\end{array}$ & $\begin{array}{l}5.3 \\
4.7 \\
0.5\end{array}$ & $2.1-8.4$ \\
\hline $\begin{aligned} \text { Urinary } & \text { (non-infectious) } \\
- & \text { Urinary retention } \\
- & \text { Renal Failure (requiring dialysis) }\end{aligned}$ & $\begin{array}{l}7 \\
6 \\
1\end{array}$ & $\begin{array}{l}3.7 \\
3.2 \\
0.5\end{array}$ & $1.0-6.4$ \\
\hline Bleeding (other than surgical) & 0 & 0 & \\
\hline Other $^{1}$ & 8 & 4.2 & 1.4-7.1 \\
\hline SURGICAL complications & 34 & 17.9 & 12.4-23.3 \\
\hline Anastomotic leak & 7 & 3.7 & $1.0-6.4$ \\
\hline Anastomotic ulcer and/or anastomotic bleeding & 3 & 1.6 & $0-3.4$ \\
\hline $\begin{aligned} & \text { Surgical site infection (SSI) } \\
&- \text { Superficial incisional SSI } \\
&- \text { Deep incisional SSI } \\
&- \text { Organ/organ space SSI }\end{aligned}$ & $\begin{array}{c}23 \\
5 \\
3 \\
15\end{array}$ & $\begin{array}{c}12.1 \\
2.4 \\
1.6 \\
7.9\end{array}$ & $7.5-16.7$ \\
\hline Surgical site bleeding & 7 & 3.7 & $1.0-6.4$ \\
\hline Wound dehiscence and/or bleeding & 9 & 4.7 & $1.7-7.8$ \\
\hline Reoperation & 15 & 7.9 & $4.1-11.7$ \\
\hline Stoma complication (stoma necrosis) $(n=24)^{2}$ & 1 & 4.2 & $0-1.6$ \\
\hline
\end{tabular}

This article is protected by copyright. All rights reserved. 
LEGEND: COPD: chronic obstructive pulmonary disease; CVA: cerebrovascular accident; TIA: transient ischemic attack; SSI: surgical site infection; ${ }^{1}$ other non-surgical complications were: decubitus, SIADH, hiccups, swallowing disorder, acute ischemic lower limb, prolonged recovery (reason not clear), altered liver function tests; ${ }^{2}$ (percentage calculated on) the number of patients that received a stoma.

Table 3: Severity of in-hospital postoperative complications (Clavien-Dindo classification) ( $n=190)$

\begin{tabular}{|c|c|c|c|c|}
\hline & & $\mathbf{n}$ & $\%$ & $95 \% \mathrm{Cl}$ \\
\hline Grade 0 & No complication & & & \\
\hline Grade I & $\begin{array}{l}\text { Any deviation from the normal postoperative } \\
\text { course without the need for pharmacological } \\
\text { treatment of surgical, endoscopic and radiological } \\
\text { interventions. Acceptable therapeutic regimens are: } \\
\text { drugs as antiemetic's, antipyretics, analgesics, } \\
\text { diuretics, electrolytes and physiotherapy. This grade } \\
\text { also includes wound infections opened at bedside. }\end{array}$ & 118 & 62.1 & $55.2-69.0$ \\
\hline Grade II & $\begin{array}{l}\text { Requiring pharmacological treatment with drugs } \\
\text { other than such allowed for grade I complications. }\end{array}$ & 52 & 27.4 & 21.0-33.7 \\
\hline Grade III $^{1}$ & $\begin{array}{l}\text { Requiring surgical, endoscopic or radiological } \\
\text { intervention. }\end{array}$ & 9 & 4.7 & $1.7-7.8$ \\
\hline Grade IV ${ }^{1}$ & $\begin{array}{l}\text { Life threatening complication requiring IC/ICU } \\
\text { management including CNS complications }{ }^{2} \text {. }\end{array}$ & 9 & 4.7 & $1.7-7.8$ \\
\hline Grade V & Death & 2 & 1.1 & $0-2.5$ \\
\hline
\end{tabular}

LEGEND: IC: intermediate care; ICU: intensive care unit

${ }^{1}$ these grades can be subdivided in a and $b$, which was not applied in this study

${ }^{2}$ brain haemorrhage, ischemic stroke, sub-arachnoid bleeding, but excluding transient ischemic attacks

This article is protected by copyright. All rights reserved. 
Table 4: Outcomes for patients without $(n=118)$ and with $(n=72)$ Clavien-Dindo $\geq 2$ in-hospital postoperative complications.

\begin{tabular}{|c|c|c|c|c|c|c|c|}
\hline & \multicolumn{2}{|c|}{$\begin{array}{c}\text { Without } \\
\text { complications } \\
\mathrm{n}=118 \\
\end{array}$} & \multicolumn{2}{|c|}{$\begin{array}{c}\text { With } \\
\text { complications } \\
n=72\end{array}$} & & & $p$-value ${ }^{1}$ \\
\hline \multirow{2}{*}{$\begin{array}{l}\text { Postoperative LOS median } \\
\text { (range) }\end{array}$} & \multicolumn{2}{|c|}{7 (3-22) days } & \multicolumn{2}{|c|}{15 (5-96) days } & & & $<0.0001$ \\
\hline & $n$ & $\%$ & $n$ & $\%$ & OR & $95 \% \mathrm{Cl}$ & $p$-value ${ }^{2}$ \\
\hline Transfer to ICU & 0 & 0 & 11 & 15.3 & 0.02 & $0.001-0.39$ & $<0.0001$ \\
\hline $\begin{array}{l}\text { Unplanned readmission } \\
\text { (within } 30 \text { days of } \\
\text { discharge) }\end{array}$ & 9 & 7.6 & 7 & 9.7 & 0.766 & $0.27-2.16$ & 0.60 \\
\hline $\begin{array}{l}\text { - Due to } \\
\text { surgical }{ }^{3} \text { complications }\end{array}$ & 1 & 0.8 & 3 & 4.2 & 0.20 & $0.02-1.93$ & 0.48 \\
\hline $\begin{array}{l}\text { - Due to combination of } \\
\text { surgical }{ }^{\beta} \text { and medical } \\
\text { complications }\end{array}$ & 2 & 1.7 & 1 & 1.4 & 1.22 & $0.11-13.7$ & \\
\hline $\begin{array}{l}\text { - Due to medical } \\
\text { complications }\end{array}$ & 6 & 5.1 & 3 & 4.2 & 1.23 & $0.30-5.09$ & \\
\hline $\begin{array}{l}\text { 30-day (postoperative) } \\
\text { mortality }\end{array}$ & 1 & 0.8 & 2 & 2.7 & 0.30 & $0.03-3.36$ & 0.56 \\
\hline $\begin{array}{l}\text { 1-year (postoperative) } \\
\text { mortality }\end{array}$ & 12 & 10.1 & 11 & 15.3 & 0.628 & $0.23-1.51$ & 0.36 \\
\hline
\end{tabular}

LEGEND: ${ }^{1}$ Wilcoxon's test; ${ }^{2}$ Fisher's exact test; ${ }^{3}$ related to the primary surgery

This article is protected by copyright. All rights reserved. 
Table 5: Outcomes for patients without $(n=170)$ and with $(n=20)$ Clavien-Dindo $\geq 3$ in-hospital postoperative complications.

\begin{tabular}{|c|c|c|c|c|c|c|c|}
\hline & \multicolumn{2}{|c|}{$\begin{array}{c}\text { Without } \\
\text { complications } \\
\mathrm{n}=170 \\
\end{array}$} & \multicolumn{2}{|c|}{$\begin{array}{c}\text { With } \\
\text { complications } \\
\mathrm{n}=\mathbf{2 0}\end{array}$} & & & $p$-value ${ }^{1}$ \\
\hline \multirow{2}{*}{$\begin{array}{l}\text { Postoperative LOS } \\
\text { median (range) }\end{array}$} & \multicolumn{2}{|c|}{8 (3-77) days } & \multicolumn{2}{|c|}{21 (5-96) days } & & & 0.0012 \\
\hline & $n$ & $\%$ & $n$ & $\%$ & OR & $95 \% \mathrm{Cl}$ & $p$-value ${ }^{2}$ \\
\hline Transfer to ICU & 0 & 0 & 11 & 5.0 & 0.002 & $0.0001-0.04$ & $<0.0001$ \\
\hline $\begin{array}{l}\text { Unplanned readmission } \\
\text { (within } 30 \text { days of } \\
\text { discharge) }\end{array}$ & 13 & 7.7 & 3 & 15.0 & 0.4692 & $0.12-1.81$ & 0.38 \\
\hline $\begin{array}{l}\text { - Due to surgical } \\
\text { complications }\end{array}$ & 3 & 1.8 & 1 & 5.0 & 0.341 & $0.03-3.45$ & 0.28 \\
\hline $\begin{array}{l}\text { - Due to combination } \\
\text { of surgical and medical } \\
\text { complications }\end{array}$ & 3 & 1.8 & 0 & 0 & 0.857 & $0.04-17.18$ & \\
\hline $\begin{array}{l}\text { - Due to medical } \\
\text { complications }\end{array}$ & 7 & 4.1 & 2 & 10.0 & 0.387 & $0.08-2.00$ & \\
\hline $\begin{array}{l}\text { 30-day (postoperative) } \\
\text { mortality }\end{array}$ & 1 & 0.6 & 2 & 10.0 & 0.053 & $0.01-0.62$ & 0.30 \\
\hline $\begin{array}{l}\text { 1-year (postoperative) } \\
\text { mortality }\end{array}$ & 18 & 10.6 & 5 & 25.0 & 0.355 & $0.12-1.09$ & 0.07 \\
\hline
\end{tabular}

LEGEND: ${ }^{1}$ Wilcoxon's test; ${ }^{2}$ Fisher's exact test ${ }^{3}$ related to the primary surgery

This article is protected by copyright. All rights reserved. 
Figure 1: Flow-chart of patient selection.

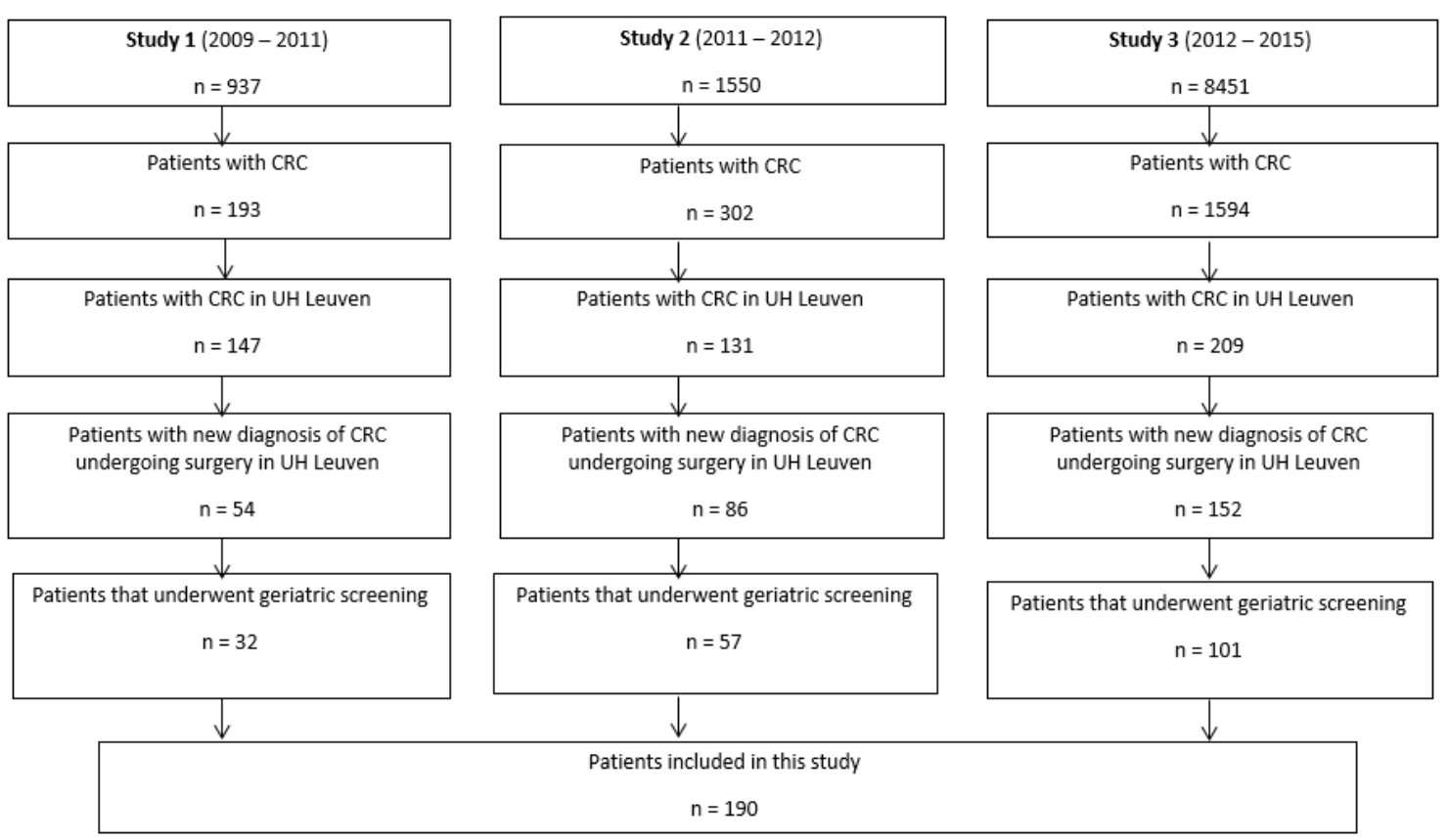

LEGEND: CRC: colorectal cancer; UH: university hospitals

This article is protected by copyright. All rights reserved. 